\title{
Pengaruh Overconfidence, Herding Effect, Self-Monitoring terhadap Investment Decision pada Masa Pandemi Covid-19
}

\author{
Hadrian dan I Gede Adiputra \\ Program Studi Manajemen Fakultas Ekonomi \& Bisnis \\ Universitas Tarumanagara \\ e-mail: eduardushadrian@gmail.com
}

\begin{abstract}
This study aims to determine the effect of overconfidence, herding effect, and selfmonitoring on investment decision in the covid-19 pandemic period. The research sample is as many as 201 respondents who have earned income and experiencing pandemic covid-19 period. This research method uses SmartPLS and by distributing questionnaires with Google form. The results of this study are there are influences of overconfidence, herding effect, and self-monitoring on investment decisionin the covid-19 pandemic period.
\end{abstract}

Keywords: Overconfidence, Herding Effect, Self-Monitoring, Investment Decision

Abstrak: Penelitian ini bertujuan untuk mengetahui pengaruh dari overconfidence, herding effect, dan self-monitoring terhadap investment decision pada masa pandemi covid-19. Sampel penelitian adalah sebanyak 201 responden yang sudah berpenghasilan dan mengalami masa pandemi covid-19. Metode penelitian ini menggunakan SmartPLS dan dengan cara menyebarkan kuesioner dengan google form. Hasil dari penelitian ini adalah terdapat pengaruh overconfidence, herding effect, dan self-monitoring terhadap investment decision pada masa pandemi covid-19.

Kata Kunci: Overconfidence, Herding Effect, Self-Monitoring, Investment Decision

\section{LATAR BELAKANG}

Pada era globalisasi seperti sekarang ini para generasi muda sudah banyak yang memiliki penghasilan yang membuat mereka harus mengolah keuangannya agar tidak dipakai untuk hal yang sia-sia salah satu cara untuk mengalokasikan uangnya tersebut adalah dengan keputusan investasi. Selain itu dengan keadaan perekonomian yang buruk akibat pandemi Covid-19 yang merupakan virus berbahaya yang diduga awal mulanya berawal dari daerah Wuhan, Cina para investor harus lebih berhati-hati dan berusaha bersikap rasional dalam melakukan kegiatan ekonomi khususnya dalam berinvestasi.Menurut Bakar dan Yi (2016) faktor-faktor psikologis memiliki dampak yang signifikan terhadap pengambilan keputusan yang dilakukan oleh seorang investor di pasar saham. Dan juga menurut Gross et al. (1998) menyatakan bahwa perilaku manusia menyerupai emosi sesaat yang secara khusus dapat mempengaruhi pengambilan keputusan.Menurut Andrikopoulos (2006) dalam behavorial finance, bias psikologis digunakan untuk mempelajari dan mengevaluasi keputusan investasi yang dapat diambil investor. Hal ini cenderung menjelaskan penyimpangan pasar dari efisiensi serta penyimpangan individu dari keuangan tradisional. Beberapa ahli ekonomi klasik seperti Gill, David Ricardo dan Adam smith mengusulkan penyertaan psikologi manusia dalam menilai kegiatan ekonomi. Dan faktor-faktor behavioural yang menarik untuk ditelitidiantaranya overconfidence, herding effect dan self-monitoring.

Bondt dan Thaler (1995) menyatakan bahwa overconfidence secara signifikan dapat mempengaruhi penilaian suatu investor ketika membuat keputusan investasi. Selain itu Menurut Tan et al. (2008) herding effect dapat menyebabkan harga saham menyimpang dari 
nilai fundamentalnya. Hal ini dapat berdampak pada sudut pandang teori penetapan harga aset dan mempengaruhi atribut model pengembalian dan risiko. Dan terakhir Kourtidis et al. (2011) yang menyatakan bahwa keputusan investasi secara signifikan dipengaruhi oleh sifat-sifat kepribadian dan bias psikologis seperti pengaruh social, self-monitoring, dan toleransi risiko. Orang dengan tingkat self-monitoring yang lebih rendah akan memakan waktu yang lebih sedikit saat membuat keputusan investasi dibandingkan dengan orang yang memiliki tingkat self-monitoring yang tinggi.

Tujuan penelitian ini adalah untuk mengetahui secara signifikan apakah pengaruh antara overconfidence terhadap investment decision, apakah pengaruh antara herding effect terhadap investment decision, dan apakah pengaruh antara self-monitoring terhadap investment decision.

\section{KAJIAN TEORI}

Overconfidence. Menurut Bondt and Pompain (2006) "overconfidence is a cognitive heuristic bias, which can be defined as unwarranted faith in one's intuitive reasoning, judgments and cognitive abilities". Kesimpulannya berdasarkan penelitian di atas overconfidence merupakan bias heuristic kognitif, yang dapat didefinisikan sebagai keyakinan yang tidak berasalan dalam penalaran intuitif, penilaian serta kemampuan kognitif seseorang.Menurut Baron (1998) "Overconfidence is essentially a distorted view of the world where the actor has expectations of personal performance that exceed the level that would be otherwise justified by an unbiased examination of the facts" pernyataan itu menjelaskan bahwa overconfidence adalah suatu pandangan yang telah menyimpang tentang dunia di mana suatu individu memiliki harapan pada kinerja dirinya untuk melebihi tingkat yang akan dibenarkan dengan pemeriksaan fakta yang tidak bias.Menurut pernyataan Brick et al. (2006) "overconfidence is a general miscalibration in beliefs, or underestimate of the variance of risky processes". Dari pernyataan tersebut dapat disimpulkan bahwa overconfidence merupakan kesalahan perhitungan umum dalam keyakinan, atau meremehkan berbagai varian proses yang beresiko sehingga membuat suatu investor biasanya akan melebih-lebihkan kemampuan prediksi mereka pada suatu hal dan melewatkan berbagai proses penting untuk menganalisis fakta yang ada serta terlalu percaya diri dalam melakukan pengelolaan market time. Hal tersebut akan membuat pengambilan keputusan investasi yang terburu-buru dan tidak tepat.

Herding Effect. Balcerzak (2014) menjelaskan "Herding is defined as activities by decision makers that are caused by interpersonal interaction and rely on taking decisions based on observation of others participants of the given community and imitating their behavior" dan dijelaskan pula "herd behavior is related to social psychology which can lead to regret aversion and cognitive dissonance".Dari pernyataan tersebut dapat dijelaskan bahwa herding didefinisikan sebagai kegiatan yang dilakukan oleh para pengambil keputusan yang disebabkan oleh interaksi interpersonal dan mengandalkan pengambilan keputusan berdasarkan pengamatan peserta lain dari komunitas yang di berikan dan meniru perlaku mereka.Menurut Baddeley (2010) "conceived herding as a response to uncertainty and individuals' perceptions of their own ignorance: people may follow the crowd because they think that the rest of the crowd is better informed". Dapat diambil dari pernyataan tersebut adalah herding merupakan tanggapan terhadap ketidakpastian dan persepsi individu atas ketidakpedulian mereka sendiri serta orang akan mengikuti suatu kelompok atau kerumunan karena mereka sendiri berpikir bahwa sisa dari kelompok atau kerumunan tersebut memiliki informasi lebih baik.Menurut pernyataan Lakonishok et al. (1992) "defined herding behavior as the behavior of many investors trading one stock in the same direction at the same time". Berdasarkan pernyataan tersebut herding difinisikan sebagai perilaku dari banyak investor yang melakukan trading pada satu saham di arah yang sama pada waktu yang bersamaan. 
Self-Monitoring. Menurut pernyataan Biais et al. (2005) "define selfmonitoring as the ability of people to adjust their personal behaviour to suit the social environment". Pernyataan itu menjelaskan bahwa self monitoring merupakan kemampuang yang dimiliki seseorang untuk menyesuaikan perilaku pribadi mereka agar sesuai dengan lingkungan social. Synder (1974) menyatakan "defines self-monitoring as how much people can modify and control their behavior in indifferent situations. The self-monitoring scale developed by Snyderin this research was used to classify the active market participants". Kesimpulan yang dapat diambil peneliti self-monitoringdapat didefinisikan sebagai pemantauan diri sebagaimana berapa banyak orang yang dapat memodifikasi dan mengendalikan perilaku mereka di dalam situasi acuh tak acuh. Skala pemantauan mandiri yang dikembangkan oleh Synder dalam penelitian ini digunakan untuk mengklasifikasikan pelaku pasar yang aktif. Berdasarkan penelitian (Miller \& Thayer (1988) Ia menyatakan "self monitoring is concerned with individual differences in the willingness or ability to modify behavior in accordance with the norms of situational appropriateness". Pernyataan tersebut menjelaskan bahwa self monitoring berkaitan dengan individu dalam kemauan atau kemampuan untuk memodifikasi perilaku sesuai dengan normanorma kesesuaian situasional.

Investment Decision. Menurut Sharpe (1964) "The world of investment can be variable but, through research and keeping your head straight, you can be successful. Every investor wants to make optimal investment decisions". Pernyataan tersebut menjelaskan bahwa dunia investasi dapat bervariasi tetapi, melalui penelitian dan tetap mempertahankan pikiran maka seseorang bisa sukses. Dan setiap investor ingin membuat investment decision yang optimal. Jadi kesimpulannya investment decision merupakan sebuah proses melalui berbagai penelitian dan analisis serta tetap mempertahankan pikiran untuk melakukan investasi.

Menurut penelitian Kishori and Kumar (2016) yang menyatakan ",investment decisions are made to seek better returns in the future by sacrificing immediate advantages." Jadi berdasarkan pernyataan tersebut investment decisionmerupakan sesuatu yang dibuat untuk mencari pengembalian yang lebih baik di masa depan dengan mengorbankan keuntungan langsung. Jagongo and Mutswenje (2014) menyatakan "the investment decisions are rather sophisticated and so it requires considerable brainstorming". Pernyataan tersebut menjelaskan bahwa investment decision merupakan sesuatu yang canggih dan membutuhkan waktu yang banyak untuk brainstorming sehingga seorang investor bisa meminimalisir kesalahan sebelum berinvestasi.

Kaitan antara overconfidence dengan investment decision. Berdasarkan penelitian dari Bondt and Thaler (1995) ia menyatakan bahwa overconfidence secara signifikan mempengaruhi penilaian investor saat membuat investment decision. Kemampuan, keberhasilan, dan probabilitas akurasi informasi ditaksir atau diperkirakan terlalu tinggi oleh investor. Menurut Odean (1998) ia menunjukkan bahwa overconfidence menyebabkan volume perdagangan meningkat dan akhirnya pasar keuangan akan terpengaruh secara langsung. Karena, traders yang terlalu percaya diri percaya bahwa informasi yang lebih tepat menunjukkan hasil dalam bobot informasi tersebut sangat signifikan. Berdasarkan uraian di atas maka hipotesis pertama adalah: $\mathrm{H}_{1}$ : Overconfidence memiliki pengaruh terhadap Investment Decision.

Kaitan antara herding effect dengan investment decision. Menurut penelitian Messis and Zapranis (2014) dikatakan bahwa keberadaan dari herding merupakan faktor risiko tambahan bagi investor. Jadi, ukutan volatilitas dipengaruhi secara positif oleh keberadaan herding behavior. Hal tersebut didukung oleh pernyataan Caparrelli et al. (2004) yang menyatakan bahwa herding effectadalah salah satu alasan untuk terjadinya gelembung spekulatif. Faktor 
herding dapat menghasilkan pengambilan keputusan yang lebih baik dengan mengumpulkan informasi yang menguntungkan. Berdasarkan uraian di atas maka hipotesis kedua adalah: $\mathrm{H}_{2}$ : Herding Effect memiliki pengaruh terhadap Investment Decision.

Kaitan antara self-monitoring dengan investment decision. Berdasarkan penelitian Kourtidis et al. (2011) ia menjelaskan bahwa keputusan investasi sangat dipengaruhi oleh berbagai sifat kepribadian dan bias psikologi seperti pengaruh sosial, risk tolerance dan self monitoring. Orang dengan self-monitoring yang rendah akan memakan waktu yang lebih sedikit untuk melakukan keputusan investasi. Menurut Eysterand Rabin (2005) mereka berpendapat bahwa investor yang memiliki lower self-monitoring cenderung meremehkan sejauh mana trades investor lain terkait dengan informasi mereka sehingga pada dasarnya self-monitoring dapat mempengaruhi investment decision. Berdasarkan uraian di atas maka hipotesis ketiga adalah $\mathrm{H}_{3}$ : Self-Monitoring memiliki pengaruh terhadap Investment Decision.

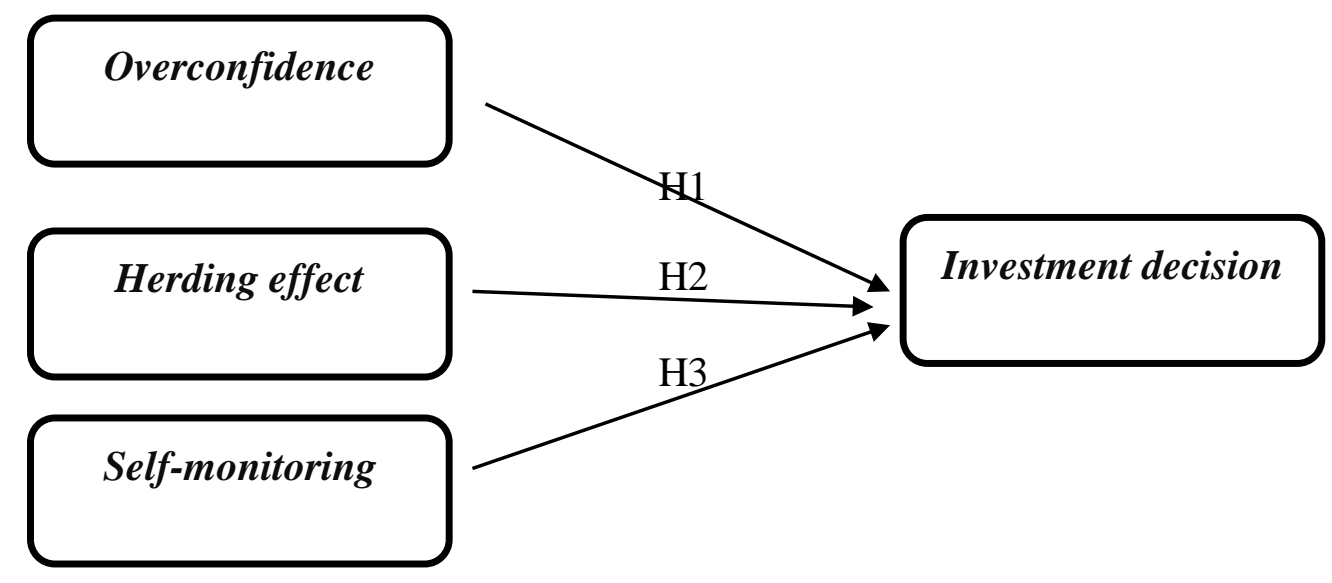

Gambar 1. Model Penelitian

\section{METODOLOGI}

Desain penelitian yang digunakan pada studi penelitian ini yaitu kausal dengan teknik pengambilan sampel secara kuantitatifdan pengumpulan data dengan cross-sectional dengan tujuan agar dapat mengumpulkan data yang relevan untuk menemukan jawaban atas pertanyaan penelitian.Populasi penelitian ini adalah individu-individu yang sedang mengalami masa pandemi Covid-19 yang berlokasi di Indonesia. Teknik pengambilan sampel dalam penelitian ini adalah nonprobability samplingdanmenggunakan cara mengambil data purposive sampling.

Penelitian ini menggunakan 201 responden, yang di antara nya 144 Laki-laki dan 57 lakilaki. Mayoritas berusia 22-26 tahun dengan tingkat pendidikan rata-rata merupakan lulusan SMA dan S1. Mayoritas responden memiliki penghasilan atau pendapatan berkisar Rp 5.100.000- Rp 8.000.000 dalam sebulan dengan rata-rata pengalaman bekerja yang dimiliki di bawah satu tahun hingga tiga tahun. Instrumen diadaptasi dari penelitian terdahulu untuk mengukur variabel penelitian seperti yang tertera di dengan menggunakan skala Likert lima poin dengan 1 menunjukan "sangat tidak setuju" dan 5 menunjukan "sangat setuju". Tabel 1 menunjukan pengukuran masing-masing variabel dan sumbernya, instrumen tersebut telah dilakukan analisis validitas dengan hasil analisis convergent validity yaitu nilai loading factor seluruh indikator seluruh variabel menunjukan hasil diatas 0,7(Henselet et al., 2009) dan nilai AVE seluruh variabel lebih besar dari 0,5 (Fornell and Larcker, 1981). Analisis discriminant validity menunjukan hasil nilai cross loading tiap indikator variabel lebih besar dari korelasi antar variabel lainnya sehingga seluruh instrumen dinyatakan valid. Sementara untuk analisis 
reliabilitas didasarkan pada nilai cronbach's alpha dan composite reliability yang masing masing hasil menunjukan nilai lebih dari 0,7 sehingga semua indikator dalam penelitian adalah reliabel. (Hair et al., 2010: 709).

Tabel 1. Variabel data Pengukuran

\begin{tabular}{|c|c|c|}
\hline \multicolumn{1}{|c|}{ Variabel } & Jumlah Item & Sumber \\
\hline $\begin{array}{c}\text { Variabel Bebas } \\
\text { 1. Overconfidence }\end{array}$ & 5 & Mumaraki \& Nasieku (2016) \\
2. Herding Effect & 3 & $\begin{array}{c}\text { Kengatharan \& Kengatharan } \\
\text { (2014) }\end{array}$ \\
3. Self-Monitoring & 4 & $\begin{array}{c}\text { Biais et al. } \\
\text { (1986) }\end{array}$ \\
\hline $\begin{array}{c}\text { Variabel Terikat } \\
\text { 1. Investment Decision }\end{array}$ & 5 & Kourtidis et al. (2011) \\
\hline
\end{tabular}

\section{HASIL UJI STATISTIK}

Berikut analisis data secara singkat:

Tabel 2. Hasil analisis Average Variance Extracted

\begin{tabular}{|c|c|}
\hline Variabel & Average Variance Extracted (AVE) \\
\hline Herding Effect & 0.664 \\
\hline Investment Decision & 0.653 \\
\hline Overconfidence & 0.613 \\
\hline Self-Monitoring & 0.726 \\
\hline
\end{tabular}

Tabel 3. Hasil Analisis Loading Factor

\begin{tabular}{|c|c|c|c|c|}
\hline & $\begin{array}{c}\text { Herding } \\
\text { Effect }\end{array}$ & $\begin{array}{c}\text { Investment } \\
\text { Decision }\end{array}$ & Overconfidence & $\begin{array}{c}\text { Self- } \\
\text { Monitoring }\end{array}$ \\
\hline HE1 & 0.752 & & & \\
\hline HE2 & 0.854 & & & \\
\hline HE3 & 0.835 & & & \\
\hline ID1 & & 0.858 & & \\
\hline ID2 & & 0.740 & & \\
\hline ID3 & & 0.768 & & \\
\hline ID4 & & 0.826 & & \\
\hline ID5 & & 0.843 & & \\
\hline OC1 & & & 0.798 & \\
\hline
\end{tabular}




\begin{tabular}{|l|l|l|l|l|}
\hline OC2 & & & 0.772 & \\
\hline OC3 & & & 0.790 & \\
\hline OC4 & & & 0.782 & \\
\hline OC5 & & 0.774 & \\
\hline SM1 & & & & 0.830 \\
\hline SM2 & & & 0.896 \\
\hline SM3 & & & 0.827 \\
\hline
\end{tabular}

Tabel 4. Hasil Analisis Reliabilitas

\begin{tabular}{|c|c|c|}
\hline Variabel & $\begin{array}{c}\text { Cronbach's } \\
\text { Alpha }\end{array}$ & $\begin{array}{c}\text { Composite } \\
\text { Reliability }\end{array}$ \\
\hline Herding Effect & 0.750 & 0.856 \\
\hline Investment Decision & 0.866 & 0.904 \\
\hline Overconfidence & 0.842 & 0.888 \\
\hline Self-Monitoring & 0.810 & 0.888 \\
\hline
\end{tabular}

Tabel 5. Hasil Pengujian Hipotesis

\begin{tabular}{|l|c|c|c|}
\hline \multicolumn{1}{|c|}{ Hipotesis } & $\begin{array}{c}\text { Path } \\
\text { Coefficient }\end{array}$ & t-statistics & p-values \\
\hline $\mathrm{H}_{1}$ Overconfidence ->investment decision & 0,291 & 4,616 & 0,000 \\
\hline $\mathrm{H}_{2}$ Herding Effect ->investment decision & 0,578 & 9,975 & 0,000 \\
\hline $\mathrm{H}_{3}$ Self-Monitoring ->investment decision & 0,129 & 3,119 & 0,002 \\
\hline
\end{tabular}

Berdasarkan hasil pengujian hipotesis di atas yang terdapat pada tabel 2, membuktikan bahwa seluruh hipotesis tidak ditolak. Hasil tersebut di dasarkan atas nilai t-statistics yang di hasilkan yaitu yang lebih besar dari nilai minimum yaitu 1,96 serta nilai p-values yang lebih kecil dari batas minimum nya yaitu sebesar $\alpha=0,05$.

\section{DISKUSI}

Berdasarkan hasil pengujian pada hipotesis pertama $\left(\mathrm{H}_{1}\right)$ terbukti Overconfidence memilki pengaruh terhadap Investment Decision. Hal ini didukung oleh penelitian Bondt and Thaler (1995) yang menyatakan bahwa Overconfidencesecara signifikan mempengaruhi penilaian investor saat membuat investment decision. Jadi seorang individu harus selalu melakukan penelitian dalam melakukan investasi dan jangan sampai terlalu percaya diri. Pada hipotes kedua $\left(\mathrm{H}_{2}\right)$ terbukti Herding Effect memiliki pengaruh terhadap Investment Decision. Hal ini didukung oleh penelitian Tan, Chiang, Mason \& Nelling (2008) menyatakan bahwa herding effect dapat memberikan dampak pada perubahan harga saham. Jadi suatu individu harus selalu menganalisi serta mengawasi jalannya pasar saham sekaligus mempelajari bagaimana investor lain berinvestasi agar dapat menentukan pilihan terbaik. Pada hipotesis ketiga $\left(\mathrm{H}_{3}\right)$ terbukti Self-Monitoring memiliki pengaruh terhadap Investment Decision. Hal ini didukung oleh penelitian Kourtidis et al. (2011) yang menyatakan bahwa keputusan investasi sangat dipengaruhi oleh self-monitoring. Jadi sebagai seorang investor harus selalu melakukan pemantauan diri agar dapat beradaptasi jika mendapatkan situasi pasar saham yang berbeda. 


\section{KESIMPULAN}

Suatu individu harus selalu dapat menjaga diri mereka agar tidak merasa terlalu percaya diri walau memiliki banyak pengetahuan agar dapat selalu menentukan pilihan investasi secara rasional. Begitu juga dengan herding effectsebagai investor harus selalu memperhatikan pasar saham agar dan mengamati investor lain agar dapat mengurangi kesalahan ketika melakukan pengambilan keputusan investasi. Selanjutnya bagi seseorang dengan high self-monitoring akan dapat melakukan pengambilan keputusan yang lebih baik dibandingkan dengan seseorang yang memiliki low self-monitoring karena individu dengan high self-monitoring yang tinggi akan selalu melakukan pemantauan diri sehingga akan selalu melakukan evaluasi pada dirinya.

Untuk perusahaan yang sedang mengalami kesulitan pada masa pandemi Covid-19, diharapkan dapat melakukan penyuluhan maupun edukasi bagi karyawannya agar dapat bertindak lebih pintar dalam masa krisis ekonomi dan juga agar dapat berinvestasi dengan baik dan melakukannya dalam kehidupan sehari-hari.Dan juga bagi peneliti selanjutnya, diharapkan agar dapat memperluas jangkauan wilayah sampel yang akan ditetapkan, dan melakukan penambahan jumlah sampel agar dapat mewakili atau merepresentasikan seluruh karateristik dari sampel penelitian sehingga dapat memperkuat dan memperbaiki penelitian.

\section{DAFTAR PUSTAKA}

Andrikopoulos, P. (2006). Moden finance vs. behaviourial finance: an overview of key concepts and major arguments. Working paper, Leicester Business, De Montfort University.

Adel, B. \& Mariem, T. (2013). The impact of overconfidence on investors' decisions. Business and Economic Research, 3(2), pp. 53-75.

Bakar, S. \& Yi, A. N. C. (2016). The impact of psychological factors on investors' decision making in Malaysian stock market: A case of Klang Valley and Pahang. Procedia Economics and Finance, 35, 319-328.

Biais, B., Hilton, D., Mazurier, K., \& Pouget, S. (2005). Judmental overconfidence, selfmonitoring and trading performance in an experimental financial market. The Review of Economic Studies, 72(2), pp. 287-312.

Bondt, W. and Thaler, R. H. (1995). Financial decision-making in markets and firms: a behavioural perspective. In Handbooks in Operations Research and Management Science, North Holland, Amsterdam, 9, pp. 385-410.

Hair et al.( 2010). Multivariate Data Analysis, Seventh Edition. Pearson Prentice Hall.

Hair, J. F. Jr., Black, W. C., Babin, B. J., \& Andersen, R. E. (2014). Multivariate Data Analysis. Edinburgh Gate, Harlow: Pearson Education Limited.

Henseler, J., Ringle, C. M., \& Sinkovics, R. R. (2009). The use of partial least squares path modeling in international marketing. In New challenges to international marketing (pp. 277-319). Emerald Group Publishing Limited

Kengatharan, L. \& Kengatharan, N. (2014). The influence of behavioral factors in making investment decisions and performance: study on investors of Colombo stock exchange, Sri Lanka. Asian Journal of Finance \& Accounting, 6(1).

Kourtidis, D., Servic, Z., \& Chatzoglou, P. (2011), Investors' trading activity: a behavioural perspective and empirical results. The Journal of Socio-Economics, 40(5), pp. 548-557. 
Mumaraki, J. N. \& Nasieku, T. (2016). Effect of Overconfidence on Individual Investment Decision: Evidence from the Investment Services Sector in Kenya. the international journal of business \& management, 4(10), pp. 254-261.

Odean, T. (1998). Volume, volatility, price, and profit when all traders are above average. The Journal of Finance, 53, pp. 1887-1934.

Odean, T. (1998). Are investors reluctant to realize their losses?. The Journal of finance, 53(5), pp. 1775-1798.

Rahman, M. \& Soon Shen Gan. (2020). Generation Y investment decision: an analysis using behavioural factors.Managerial Finance, Emerald Group Publishing Limited.

Tan, L., Chiang, T. C., Mason, J. R., \& Nelling, E. (2008). Herding behavior in chinese stock markets: an examination of A and B shares. Pasicif-Basin Finance Journal, 16(1), pp. 61-77. 